\title{
Investigation into Building Energy Consumption between Theory, Experiment and Modelling
}

\author{
Firas J. Khusaifan \\ Mechanical and Marine Engineering, Liverpool John Moores University, UK \\ Received 12 May 2018, Accepted 15 July 2018, Available online 17 July 2018, Vol.8, No.4 (July/Aug 2018)
}

\begin{abstract}
The primary purpose of this project plan is to outline the road map to achieve the aim of the project. This project investigates the energy consumption and associated energy losses that occur across an infrastructure, and to make recommendations with possible improvements to the infrastructure resulting in reduction of the energy losses. The Engineering Workshop building on the Byrom Street, campus of Liverpool John Moores University have been planned to investigate. Detailed plan is made to achieve the objectives of this project. The plan includes the energy losses calculated between the Workshop and the outside environment through three different methods; Theoretical calculation, Experimental real time Data logging and suitable Computer Modelling. This investigation plan traverse with Literature review in first week and collection of data required in each of the three methods for a span of eleven weeks, among the parameters like heat transfer rate, thermal conductivity, temperature recordings over sustained period, and the Workshop building material properties are collected. The energy losses occurred through the workshop building are determined from the three methods. Finally, within two weeks, all the three methods results are compared and validated. In conclusion, the investigation results hope to assert the energy losses determined by the three different models are identical. And any improvements to the Engineering Workshop building infrastructure that would minimize the energy losses and henceforth reduction in the building energy consumption are recommended. The investigation terminates with Project report documentation and submission by week 14; presentation and oral examination of the project planned in week 15-16.
\end{abstract}

Keywords: Energy consumption, Energy losses etc.

\section{Introduction}

The World's energy need is from Hydrocarbon (Fossil Fuel) energy contributes $28 \%$ from Coal, $40 \%$ from Oil, $20 \%$ from Natural gas and $12 \%$ from renewable energy (Energysavingsecrets.co.uk, 2016). 88\% of the energy is used from non-renewable resource, which leads to high emission of carbon dioxide. According to NASA the carbon dioxide level in 1950 was 300 part per million (ppm), and today in 2017 it has increased to 400 (ppm). This cause of the global warming affected the planet in many different aspects. First the Global Mean Sea Level (GMSL) from 1870 to 2014 rose by $195 \mathrm{~mm}$ an average of $1.44 \mathrm{~mm} /$ year (Church and White, 2006). Moreover, the globe surface temperature rose $0.87 \mathrm{C}$ from 1880 to 2015 (NASA/GISS,2016). These are some of the issues that burning fossil fuels have brought to the environment.

According to United Nations and BBC there are 171 countries that signed Paris climate deal in 2015

*Corresponding author's ORCID ID: 0000-0003-4289-2927 DOI: https://doi.org/10.14741/ijcet/v.8.4.16
"Transforming our world: The 2030 Agenda for Sustainable Development" (United Nations, 2015), until we reach the year 2030 efforts must be made to reduce the energy consumption by applying energy management.

\section{Project Aims and Objectives}

This project aims to investigate the energy requirements for the Engineering Workshop on the Byrom Street campus of Liverpool John Moores University. This investigation will consider the workshop building energy consumption and associated energy losses that occur due environmental condition both internally and externally.

The investigation aims to:

- Monitor in real time all the data related to the energy consumption and energy loss for the workshop through a sustained period.

- Calculate the energy losses between the workshop and the outside environment utilising a number of 
method including; Theoretical calculation, real time data logging and suitable computer modelling.

- Evaluate the methods employed and review their outcomes.

- Identify possible improvements to the workshop infrastructure to reduce energy losses in the building.

\section{Nomenclature}

\begin{tabular}{|c|c|c|}
\hline Symbol & Parameter & Units \\
\hline$\dot{\mathrm{Q}}$ & Heat transfer rate & (W), (Watt) \\
\hline $\mathrm{k}$ & Thermal conductivity & $\begin{array}{l}\text { (W/m.K), (watts } \\
\text { per meter-kelvin) }\end{array}$ \\
\hline $\mathrm{h}$ & Conduction & $\begin{array}{l}\left(\mathrm{W} / \mathrm{m}^{2} \cdot \mathrm{K}\right) \text {, (watts per } \\
\text { square meter kelvin) }\end{array}$ \\
\hline $\mathrm{R}$ & Thermal resistance & $\begin{array}{l}\text { (K/W), (Kelvin per } \\
\text { Watt) }\end{array}$ \\
\hline I & Electric current flow & (amp), ( ampere) \\
\hline U & $\begin{array}{c}\text { Heat transfer } \\
\text { coefficient }\end{array}$ & $\begin{array}{l}(\mathrm{W} / \mathrm{K}),(\mathrm{Watt} \text { per } \\
\text { Kelvin) }\end{array}$ \\
\hline $\mathrm{T}$ & Temperature & (C), (Celsius) \\
\hline A & Area & $\left(m^{2}\right)$, (meter square) \\
\hline $\mathrm{L}$ & Length & (m), (meter) \\
\hline $\mathrm{V}$ & Voltage & (V),(voltage) \\
\hline $\operatorname{Re}$ & Electric resistance & ohms \\
\hline
\end{tabular}

\section{The Engineering Workshop}

This project will investigate the energy requirements for the Engineering Workshop on the Byrom Street campus of Liverpool John Moores University as shown in figure 1. The Engineering Workshop location is in United Kingdom, Merseyside, Liverpool city, GPS coordinates (latitude and longitude) are (53.412445, 2.980584).

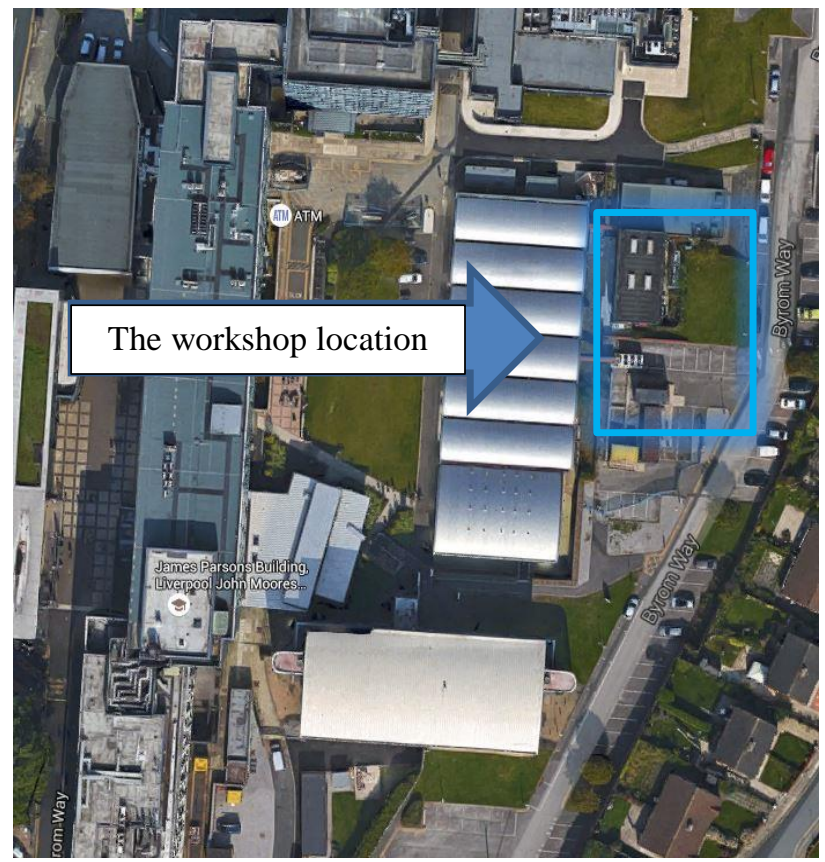

Figure 1 The Engineering Workshop
The Engineering Workshop building comprise of two sections; the Office as shown in figure 2 and the Workshop as shown in figure 3 .

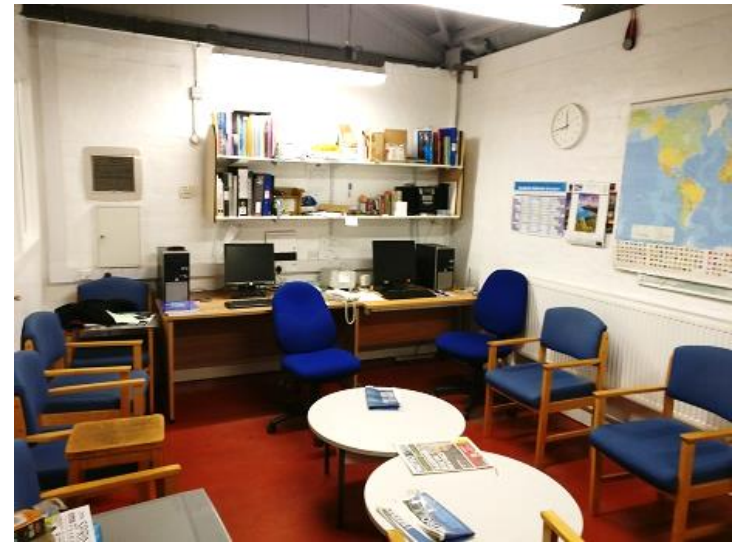

Figure 2: Office

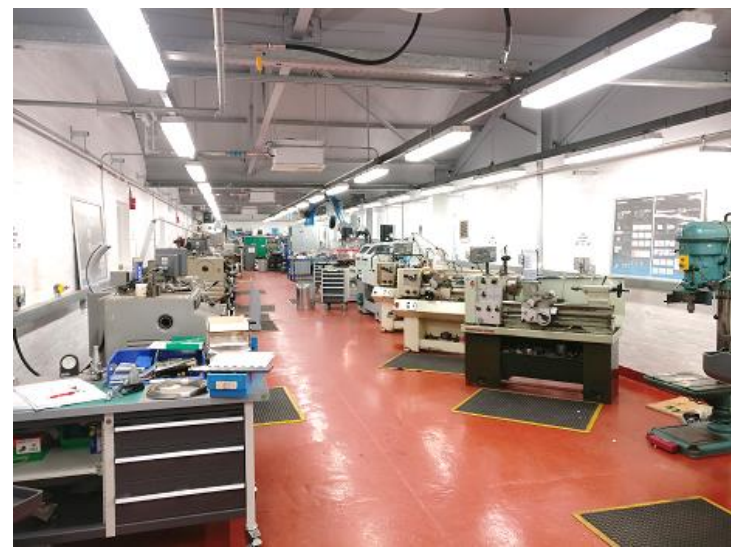

Figure 3: Workshop

From figures 2 and 3, it could be seen that the Office is equipped with Computers, lights, heat radiator and microwave, and the Workshop do have 3 heaters, lights and machines. The heater system in the Workshop made by Biddle $(\mathcal{C}$, it has cassette fan convertor running on low-pressure hot water under an alternative water side control. The light system in the Workshop are fixed with fluorescent tube sets which includes light tubes, starter and ballast screwfix (transformer). All these machines and heater system in the Office and the Workshop will affect the overall temperature. And the existing light system affecting the energy consumption.

The Engineering Workshop building material comprise of aluminium for exterior building cladding, brickwork for the walls, glass fibre slab between the cladding and the external walls, plasterboard for internal walls and concrete reinforced for the floor.

\section{Literature review (Research)}

\section{A/ General information}

Energy management is defined as 'The efficient and effective use of energy to maximize profits [minimize costs] and enhance the competitive position' (Capehart, Turner and Kennedy, 2008). 
According to (gov.uk) the highest demand of electrical energy with average annual consumption for households in the United Kingdom; Space heating 6754 (kWh), Water heating $1338(\mathrm{kWh})$, Plasma television $658(\mathrm{kWh})$ and Lighting $537(\mathrm{kWh})$ (Intertek Testing \& Certification Ltd, 2012).

The outdoor lighting is renewable resource and it accounts to the fifth of global power usage, the development in the light technology like LED can save up to $40 \%$ of the electricity used (Wojnicki, Ernst and Kotulski, 2016). At the workplace, the lighting consumes $1.3 \mathrm{Kh} / \mathrm{d}$ per person (MacKay, 2008). The lighting percentage of energy consumption in the UK is different by the building type as shown in Table 1 .

Table1: Lighting percentage of energy consumption in the UK

\begin{tabular}{|c|c|}
\hline Building type & $\begin{array}{c}\text { Typical percentage of energy } \\
\text { consumption by lighting }\end{array}$ \\
\hline Bank & $19 \%$ \\
\hline Factories & $15 \%$ \\
\hline Hotels & $9 \%$ \\
\hline Offices & $16-20 \%$ \\
\hline Schools & $9-12 \%$ \\
\hline Supermarkets & $11 \%$ \\
\hline
\end{tabular}

Source:- Beggs, C., 2010. Energy: management, supply and conservation. Routledge.

There are so many ways to reduce the lighting energy consumption by using energy efficient lighting (Beggs, 2010), (Capehart, Turner and Kennedy, 2008) and/or apply the artificial lighting design that include terms like: - Average illuminance ( $\mathrm{E}$ av ), Lighting design lumens $(\rho)$, Utilization factor (UF) and Maintenance factor (MF) (Beggs, 2010).

Liverpool average temperature from 1981 to 2010 in winter is 7.2C, in summer 19.7C (Metoffice.gov.uk, 2016). According to Health and Safety Executive (HSE), the law doesn't state a minimum or maximum temperature at workplace, but advice it should be at least 16C or 13C if the worker do physical effort (Hse.gov.uk, 2016) and (Capehart, Turner and Kennedy, 2008). ASHRAE standard recommend comfort temperature must be not less than $19.4 \mathrm{C}$ with $30 \%$ of relative humidity (Tom, 2016).

\section{$B$ / Initial theory and calculation method}

Heat Transfer calculation requires some terms to be defined, equations and values to be determined; like we need to know to calculate Heat transfer rate $(\dot{Q}, W)$. The Heat transfer rate $(\dot{Q}, W)$ is 'the quantity of heat transferred per unit time' (Cengel, Ghajar and Kanoglu, 2015). The Thermal conductivity $(\mathrm{k}, \mathrm{W} / \mathrm{m} . \mathrm{K})$ can be defined as the rate of heat transfer through a unit thickness of the material per unit area per unit temperature difference' (Cengel, Ghajar and Kanoglu, 2015). The Conduction ( $\mathrm{h}, \mathrm{W} / \mathrm{m} 2 . \mathrm{K}$ ) can be defined as 'the mode of energy transfer between solid surface and adjacent liquid or gas that is in motion, and it involves the combined effects of conduction and fluid motion'. (Cengel, Ghajar and Kanoglu, 2015).
Steady heat conduction in plane walls

Rate of heat conduction $\alpha \frac{(\text { Area }) \text { (temperature difference) }}{\text { Thickness }}$

Or

$\dot{\mathrm{Q}}$ cond $=\mathrm{kA} \frac{T 1-T 2}{\Delta x}=-\mathrm{kA} \frac{\Delta T}{\Delta X}(\mathrm{~W}),($ Watt $)$
$\dot{\mathrm{Q}}$ cond $=-\mathrm{kA} \frac{d T}{d x}(\mathrm{~W}),($ Watt $)$

After we perform the integration we will get

Q cond, wall $=\mathrm{kA} \frac{T 1-T 2}{l}(\mathrm{~W}),(\mathrm{Watt})$

Thermal resistance

Q cond, wall $=\frac{T 1-T 2}{R \text { wall }}(\mathrm{W}),(\mathrm{Watt})$

Where

R cond $=\frac{1}{h A} \quad(\mathrm{~K} / \mathrm{W}),($ Kelvin $/$ Watt $)$

$\mathrm{R}$ wall $=\frac{L}{k A} \quad(\mathrm{~K} / \mathrm{W}),($ Kelvin $/$ Watt $)$

The Thermal resistance in multilayer wall

The thermal resistance $(R)$ is similar to the electric current flow (I) as in equation $(7,8)$

$$
\begin{aligned}
& \mathrm{I}=\frac{V 1-V 2}{R e} \quad(\mathrm{amp}) \\
& \dot{\mathrm{Q}} \mathrm{conv}=\frac{T 1-T 2}{R \operatorname{conv}}(\mathrm{W}),(\mathrm{Watt})
\end{aligned}
$$

Overall heat transfer coefficient $U$ is usually used in the calculation deal with heat exchanger and the heat transfer through windows.

$\dot{\mathrm{Q}}=\mathrm{UA} \Delta \mathrm{T}(\mathrm{W}),(\mathrm{Watt})$

Where

$\mathrm{UA}=\frac{1}{R \text { total }}(\mathrm{W} / \mathrm{K}),(\mathrm{Watt} /$ Kelvin $)$

The total heat transfer rate $(\dot{Q}, W)$ is the final value of the heat transfer from the workshop

$\dot{\mathrm{Q}}$ total $=\frac{T \alpha 1-T \alpha 2}{R \text { total }}(\mathrm{W}),(\mathrm{Watt})$

Where

$\mathrm{R}$ total $=\mathrm{R}$ conv1 $+\mathrm{R} \operatorname{conv} 2+\mathrm{R} 3+\mathrm{R} 4+\ldots+\mathrm{R} \mathrm{n}=$ $\frac{1}{h 1 A}+\frac{1}{h 2 A}+\frac{L 1}{k 1 A}+\frac{L 2}{k 2 A}+\cdots+\frac{L n}{k n A}(\mathrm{~W})(12)$

The thermal conductivity $(\mathrm{k})$ in the materials used in the workshop as shown in table 2 
Table 2 Thermal conductivity $(\mathrm{k})$ of the materials used in the workshop

\begin{tabular}{|c|c|}
\hline aluminum alloy, typical & \\
\hline $190 \mathrm{~W} / \mathrm{m} \mathrm{K}$ & (McMullan, 2012) \\
brickwork internal & \\
$0.56 \mathrm{~W} / \mathrm{m} \mathrm{K}$ & (McMullan, 2012) \\
\hline concrete reinforced & \\
\hline $2.3 \mathrm{~W} / \mathrm{m} \mathrm{K}$ & (McMullan, 2012) \\
\hline plasterboard & \\
\hline $0.16 \mathrm{~W} / \mathrm{m} \mathrm{K}$ & (Beggs, 2015) \\
\hline glass, window pane & \\
\hline $1.022 \mathrm{~W} / \mathrm{mK}$ & (McMullan, 2012) \\
\hline glass fiber slab & (Beggs, 2015) \\
\hline $0.035 \mathrm{~W} / \mathrm{mK}$ & \\
\hline
\end{tabular}

\section{This calculation will achieve the following}

1/ the thermal resistance (R) for each building material of the Engineering workshop.

2/ the thermal resistance (R) for each fluid contact conduction of the Engineering workshop.

3/ The total thermal resistance (R).

Based on the real outside ambient temperature of the Engineering Workshop we will determine the Heat transfer rate $\mathrm{Q}$ for the Engineering Workshop, which will indicate the real heating requirement in Watts.

\section{C/ Experimental Method}

To establish the environmental conditions and hence energy transfers and their associated losses it is proposed to data log the ambient and room temperature over a sustained period of time. To achieve this real time monitoring, 12 Digital Loggers (ELITECH $®$ RC-5 as shown in figure 4 are installed.

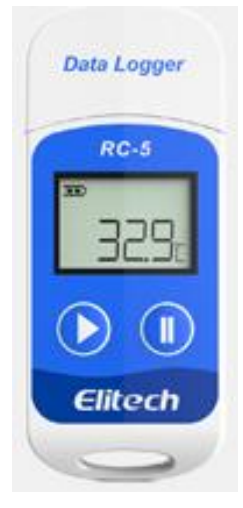

Figure 4 Digital Logger (ELITECH $®$ RC-5)

1 Digital Logger is installed in the office and 10 Digital Loggers are installed in the workshop room at different places and different levels to measure the actual temperature at respective places and levels and one Digital Logger outside the building for a period of one month. The period is sufficient to analyse the temperature inside the room from the 11 installed locations, and also check the validity of the hand calculation and the CFD module. The Data logger has been set for with 30-minute delay to ensure that after being placed the starting temperature is not affected by physical contact caused by human hand temperature, the recording is adjusted to collect temperature every 15 minutes, with disabled pause button.

\section{D/ Modelling}

In the simulation modelling method, we will build model for the Workshop using the Solidworks $2017 \AA$ software, and will apply the material from Solidworks 2017 ® library since it is updated with all required building material. The boundary conditions will be the outside wall temperature, gravity and the heat source. Detailed plan for reminder of the project (Planning)

Project plan spans over 13-16 Weeks period; traverse in following phases and schedule as shown in figure 5

\section{Data collection}

Data needed is collected for Engineering Workshop in Liverpool John Moores University by:

a) Measuring the building total area, the height and total volume.

b) Measuring the door and windows to calculate the heat losses.

c) Count the number of appliances (heaters and lights) to calculate the electricity consumption.

d) Get temperature recordings from digital loggers to calculate the heating requirement for the building and the heat losses.

e) Gain an understanding of the walls, ceiling ground, etc. materials to estimate the thermal resistance (R) and/or the heat transfer coefficient (U).

\section{Literature Review}

Qualitative research technique is followed; publications, books searched to acquire the required technical knowledge and skills. Finally, brainstorming sessions are conducted.

\section{Start report writing.}

\section{Report draft start and run}

\section{Data analysis}

The data analysis has four phase.

\section{A) Theory}

The theory phase calculation must be done according to the real dimensions' measurements of the workshop. Thermal resistance (R) and/or the heat transfer coefficient $(\mathrm{U})$ could be taken from books table and temperature from the recorded temperature in the data logger to calculate the heat conduction. (Q) 


\section{B) Experiment}

In the experiment, we need to collect the real temperature from inside and outside the workshop, by installing temperature data logger at different places and levels inside the workshop. Recording temperature round the clock for a period of one month.

\section{C) Modelling}

In In the modelling part (CFD) we will create a model for the workshop by using SOLIDWORKS 2017 (C) program by using real dimensions measurements, material from SOLIDWORKS 2017 (C) library and average temperature for wall boundary condition.

D) Comparing and analyzing the result

For analyzing the results, we will take all the above three parts Theory, Experiment and Modelling. Validate the results and/or justify the difference between the results.

\section{Conclusion and Recommendations}

Discuss each result, and justify if all the models determine identical results. List any recommendations that improve the quality of the heat conduction in the Workshop.

\section{Finalize report writing.}

In week 10 to 11 , finalize the report.

\section{Proofreading for the report.}

Report style, grammar and text structure checked as per guidelines.

\section{Submit the project (60\%).}

31 th March - deadline to submit the project dissertation.

\section{Presentation and oral examination (20\%).}

April/ May month planned for project presentation and oral examination.

\begin{tabular}{|c|c|c|c|c|c|c|c|c|c|c|c|}
\hline no & Activity & week & \begin{tabular}{|l|l|l|l}
1 & 2 & 3 & 4 \\
\end{tabular} & 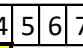 & \begin{tabular}{l|l|l}
7 & 8 & 5 \\
9
\end{tabular} & \begin{tabular}{l|l|}
9 & 10 \\
\end{tabular} & \begin{tabular}{|l|l|l|}
11 & 1 \\
\end{tabular} & \begin{tabular}{l|l}
12 & 1 \\
\end{tabular} & \begin{tabular}{|l|l|}
13 & 14 \\
\end{tabular} & & 16 \\
\hline 1 & Data collection & & & & & & & & & & \\
\hline A & Measuring the building total area & & & & & & & & & & \\
\hline$B$ & Measuring the door and windows & & & & & & & & & & \\
\hline C & Account the number of appliances & & & & & & & & & & \\
\hline $\mathrm{D}$ & Get temperature from digital logger & & & & & & & & & & \\
\hline $\mathrm{E}$ & collection thermal resistance $(\mathrm{R})$ & & & & & & & & & & \\
\hline 2 & Literature Review & & & & & & & & & & \\
\hline 3 & Start report writing & & & & & & & & & & \\
\hline 4 & Data analysis & & & & & & & & & & \\
\hline A & Theory & & & & & & & & & & \\
\hline$B$ & Experiment & & & & & & & & & & \\
\hline C & Modelling & & & & & & & & & & \\
\hline $\mathrm{D}$ & Comparing and analyzing the result & & & & & & & & & & \\
\hline 5 & Conclusion and Recommendations & & & & & & & & & & \\
\hline 6 & Finalize report writing & & & & & & & & & & \\
\hline 7 & Proofreading for the report & & & & & & & & & & \\
\hline 8 & Submit the project & & & & & & & & & & \\
\hline 9 & Presentation and oral examination & & & & & & & & & & \\
\hline
\end{tabular}

Figure 5: Gantt chart schedule

\section{Data collection and analysis}

This research comprises of lot of data collection and analysis.

1/ Metric measurement for the spaces, thickness and areas for all the workshop and the building walls, ground, ceiling, windows and doors.

2/ Calculate the thermal resistance (R) of the walls, ground and ceiling.

3/ Measure the actual temperature inside and outside the Workshop by Data logger installed at different places and different levels.

4/ Measure the existing heaters capacity.
5/ Measure the others heating sources like light, workers, machines...etc.

After obtaining all the data required for the building, we plug the data in theoretical equations and do manual calculations, perform experimental (logger data) method and simulate modelling (CFD) to analyse/compare the results. Data collection could face some problems for measuring thickness, either we need to estimate some thicknesses and/or do some damage to the structure to obtain accurate measurement. Also, Collect and calculate the thermal resistance (R) is different from source to other. There might be a problem in temperature data loggers due to 
suspended temperature recordings for unknown reasons; so, they should be daily checked. Also, the simulation may not function effectively since the model is big and have a lot of parameters; so we need to build simple model, check the result and then improve it by adding the parameters one by one.

\section{Summary}

To summarise, the consumption of hydrocarbon fuel and their environmental impact is of major concern to society. There are a number of methods to reduce energy consumption within buildings without affecting the internal environment the populous are exposed too.

In the United Kingdom, the electricity demand is high on space heating, water heating, plasma TV and lighting (Intertek Testing \& Certification Ltd, 2012). As such focusing on improving the heating efficiency of buildings by having good isolation and a controlled ventilation discharge is an appropriate approach.

The comparison and review of the three proposed methods of analysing the energy requirement of the workshop building and the identification of sustainable reductions in energy consumption would appear to be a justifiable approach.

\section{References}

Allison, I., Bindoff, N.L., Bindschadler, R.A., Cox, P.M., de Noblet, N., England, M.H., Francis, J.E., Gruber, N., Haywood, A.M., Karoly, D.J. and Kaser, G., 2011. The Copenhagen Diagnosis: Updating the world on the latest climate science. Elsevier.

BBC News. (2016). COP21 climate change summit reaches deal in Paris - BBC News. [online] Available at: http://www.bbc.co.uk/news/science-environment35084374

Beggs, C., 2010. Energy: management, supply and conservation. Routledge.

Capehart, B., Turner, W. and Kennedy, W. (2008). Guide to energy management. 6th ed. Lilburn, Ga.: Fairmont Press.

Cengel, Y., Ghajar, A. and Kanoglu, M. (2015). Heat and mass transfer. 1st ed. New York: McGraw Hill Education.

Church, J. and White, N. (2006). A 20th century acceleration in global sea-level rise. Geophys. Res. Lett., 33(1), p.n/a-n/a.

Climate.nasa.gov. (2016). Global Temperature. [online] Available at: http://climate.nasa.gov/vital-signs/globaltemperature/].
Elitech.uk.com. (2017). Cite a Website - Cite This For Me. [online] Available at: http://www.elitech.uk.com/images/index/y1.jpg

Energysavingsecrets.co.uk. (2016). Facts and Figures About Fossil Fuels. [online] Available at: http://www.energysavingsecrets.co.uk/facts-figuresfossil-fuels.html [Accessed 16 Jun. 2016].

Framework convention on climate change. (2015). [online] Paris: United Nations. Available at: http://unfccc.int/resource/docs/2015/cop21/eng/109r01 .pdf

Holman, J. (2010). Heat transfer. 1st ed. Boston [Mass.]: McGraw-Hill.

Hse.gov.uk. (2016). HSE - Temperature: Frequently asked questions. [online] Available at: http://www.hse.gov.uk/temperature/faq.htm

Intertek Testing \& Certification Ltd, (2012). Household Electricity Survey A study of domestic electrical product usage. [online] Available at: https://www.gov.uk/government/uploads/system/uploa ds/attachment_data/file/208097/10043_R66141Househo ldElectricitySurveyFinalReportissue4.pdf

MacKay, D., 2008. Sustainable Energy-without the hot air. UIT Cambridge.

McGrath, M. (2016). Nations sign historic Paris climate deal $B B C$ News. [online] BBC News. Available at: http://www.bbc.co.uk/news/science-environment36108194

McMullan, R. (2015). Environmental Science in Building. 1st ed. Basingstoke: Palgrave Macmillan

Metoffice.gov.uk. (2016). Liverpool climate information - Met Office. [online] Available at http://www.metoffice.gov.uk/public/weather/climate/gc mzggpxq\#?region=northwestengland [Accessed 17 Jun. 2016].

Senior, K. (2016). Facts and Figures About Fossil Fuels. [online] energy saving secrets. Available at: http://www.energysavingsecrets.co.uk/facts-figuresfossil-fuels.html

Tom, S. (2016). Managing Energy And Comfort Ashrae. Ashrae Journal.

Wojnicki, I., Ernst, S. and Kotulski, L. (2016). Economic Impact of Intelligent Dynamic Control in Urban Outdoor Lighting. Energies, 9(5), p.314.

Bryman, A., 2015. Social research methods. Oxford university press.

Handbook, A.S.H.R.A.E., 2001. Fundamentals. American Society of Heating, Refrigerating and Air Conditioning Engineers, Atlanta, 111.

Handbook, A.S.H.R.A.E., 2007. HVAC applications. ASHRAE Handbook, Fundamentals, (2003).

Handbook-Heating, A.S.H.R.A.E., 2008. Ventilating, and AirConditioning Systems and Equipment (IP Edition) American Society of Heating, Refrigerating and AirConditioning Engineers. 